\title{
Sitio web y aplicación móvil de control de uso del suelo a través del mapa interactivo de la región norte del estado de Guerrero, segunda fase
}

\section{Website and mobile application for land use control through the interactive map of the northern region of the state of Guerrero, second phase}

\author{
DE LEÓN-CASTREJÓN, Andrés $\dagger^{*}$, OCHOA-LÓPEZ, Ana Laura, NORIEGA-CANTÚ, David \\ Heriberto y SALGADO MORA, Gabriela
}

Universidad Tecnológica de la Región Norte de Guerrero

ID $1^{\mathrm{er}}$ Autor: Andrés, De León-Castrejón / ORC ID: 0000-0003-2864-2358, CVU CONACYT ID: 744847

ID $1^{\text {er }}$ Coautor: Ana Laura, Ochoa-López

ID $2^{\text {do }}$ Coautor: David Heriberto, Noriega-Cantú / ORC ID: 0000-0002-8215-4104, CVU CONACYT ID: 74588

ID $3^{\text {er }}$ Coautor: Gabriela, Salgado Mora

DOI: $10.35429 / J C S .2019 .9 .3 .1 .16$

Recibido: 12 de Julio, 2019; Aceptado 30 de Septiembre, 2019

\section{Resumen}

Este trabajo está fundamentado en el proyecto de estadías que realizaron tres alumnos del programa educativo de Ingeniería en Tecnologías de la Información en la Universidad Tecnológica de la Región Norte de Guerrero en el periodo de Enero - Abril de 2017, el trabajo se ha reestructurado en una segunda fase dándole continuidad al proyecto de investigación realizado en el Instituto Nacional de Investigaciones Forestales, Pecuarias y Agrícolas del Estado de Guerrero, que para obtener el tipo de tratamiento denominado paquete tecnológico de fertilización en los terrenos de siembra en la región norte del estado de guerrero, se aplica la fórmula 90-60-00 del inifap por medio de tres tablas que se encuentran al final de este trabajo en el apartado de anexo. Con esta información tecnológica y la fórmula de fertilización recomendada, (90-60-00), se sugiere la fuente y cantidades de nitrógeno y fosforo a utilizar. La fuente de nutrientes está en función del Programa de Fertilizantes, para nitrógeno, se dispuso de sulfato de amonio $(21 \% \mathrm{~N}) \mathrm{o}$ fosfonitrato (33\% N, $3 \%$ P2O5) y para fosforo, fosfato diamónico $\left(18 \%\right.$ N, $46 \%$ P2 O5) ${ }^{[8]}$.

\begin{abstract}
This work is based on the project of stays carried out by three students of the educational program of Engineering in Information Technology at the Technological University of the Northern Region of Guerrero in the period from January - April 2017, the work has been restructured into a Second phase, giving continuity to the research project carried out at the National Institute of Forestry, Livestock and Agricultural Research of the State of Guerrero, that to obtain the type of treatment called technological fertilization package in the sowing land in the northern region of the state of Guerrero, the formula 90-60-00 of the inifap is applied by means of three tables found at the end of this work in the annex section. With this technological information and the recommended fertilization formula, (90-60-00), the source and amounts of nitrogen and phosphorus to be used are suggested. The source of nutrients depends on the Fertilizer Program, for nitrogen, ammonium sulfate $(21 \% \mathrm{~N})$ or phosphonitrate $(33 \% \mathrm{~N}, 3 \% \mathrm{P} 2 \mathrm{O} 5)$ was available and for phosphorus, diammonium phosphate (18\% N, 46\% P2 O5) [8].
\end{abstract}

\footnotetext{
* Correspondencia al Autor: (andresdlc@utrng.edu.mx)

$\uparrow$ Investigador contribuyendo como primer autor.
} 


\section{Justificación}

El inifap realizó hace años un censo agrícola, el cual cuenta con información de los terrenos de siembra mismos que pertenecen a los productores de maíz ubicados en las distintas áreas agrícolas del estado de guerrero, estos terrenos son de dos tipos: de riego y de temporal, la construcción del paquete tecnológico de fertilización se realiza de manera manual, buscando la información en dicho censo, situación que resulta tediosa cada vez que se requiere hacer el paquete tecnológico.

Debido a lo anteriormente mencionado se torna necesario mejorar los algoritmos del sitio web y la aplicación móvil para realizar la construcción del paquete tecnológico de fertilización y este a su vez, permita agilizar la toma de decisiones de acuerdo con los criterios requeridos ${ }^{[4]}$.

\section{Problema}

El inifap es una institución de excelencia científica y tecnológica con liderazgo y reconocimiento nacional e internacional por su capacidad de respuesta a las demandas de conocimiento e innovaciones tecnológicas en beneficio agrícola, pecuario y de la sociedad en general ${ }^{[9]}$, se dedica al desarrollo de diferentes proyectos para el mejoramiento y rendimiento de los cultivos, ahora bien uno de estos proyectos es realizar registros de ph del suelo, superficie total del terreno a sembrar y el total de fertilizante con base a un censo agrícola. Cabe mencionar que las condiciones de cada terreno son muy diversas, se aplican algunos criterios para construir el paquete tecnológico de fertilización, lo que resulta necesario checar el censo agrícola y dependiendo de la información del terreno, se aplica una fórmula química en donde de acuerdo al grado de acidez en el ph del suelo, será determinado el tipo de fertilizante a utilizar, dicho proceso es tedioso y tardado, lo cual impacta en la toma de decisiones para conocer las cantidades en kilogramos de fertilizantes ${ }^{[8]}$.

\section{Hipótesis}

Con la mejora de los procesos en el sitio web y aplicación móvil, se podrá obtener la fuente y dosis de fertilizante que necesitan los terrenos de siembra pertenecientes a productores de maíz ubicados en la región norte del estado de guerrero.

\section{Objetivos}

\section{Objetivo general}

Mejorar el sitio web y aplicación móvil de control de uso del suelo a través del mapa interactivo de la región norte del estado de guerrero, en una segunda fase con el propósito de informar a los productores de maíz de la fuente y dosis de fertilización de sus terrenos de siembra.

\section{Objetivos específicos}

\section{Del sitio web:}

- Actualizar la base de datos inifapbd, según sea necesario.

Readecuar el nivel de seguridad a través de roles de administrador y usuario.

- Utilizar las herramientas, tales como: php, javascript, html y xampp.

- Generar información específica sobre la fuente y dosis de fertilizante para cada municipio y localidad de la región norte de guerrero.

Construir el reporte de fertilización para los productores de maíz a través de un documento en formato pdf para su consulta e impresión.

- Contratar el dominio opds.website y posteriormente hospedar el sitio web en el subdominio www.dotacionfertilizante.opds.website.

\section{De la aplicación móvil:}

- Utilizar el lenguaje de programación c\#, xaml y xamarin forms para android.

- Generar información sobre la fuente y dosis de fertilizante para cada municipio y localidad en la región norte de guerrero.

- Construir la aplicación móvil adecuada a la estructura del sitio web, con base en un menú y brindando información a los productores de maíz, de los municipios de la región norte del estado de guerrero. Conectar la base de datos del sitio web con la aplicación móvil a través de un api restful service (microservicio) para el acceso remoto entre ambas plataformas. 


\section{Marco teórico}

Las herramientas a utilizar para desarrollar el proyecto, son:

Php. Es un lenguaje de programación que se utilizará para construir nuestro sitio web, así también se puede incrustar en html para lograr mejor dinamismo, por otra parte, puede conectar la base de datos del sitio.

Enterprise Architect. Es una herramienta de diseño y análisis uml, cubriendo el desarrollo de software desde el paso de los requerimientos a través de las etapas del análisis, modelos de diseño, pruebas y mantenimiento. Se ocupará en nuestro proyecto para modelar el sitio web a través de diagramas como: casos de uso, secuencias y clases.

Xampp. Es un software que integra en una sola aplicación un servidor web como apache, interprete de php, servidor de base de datos para mysql, en nuestro caso se ocupará para construir la base de datos e interpretación del código en php de nuestras interfaces gráficas del sitio web.

Html5. Es un lenguaje que sirve para colocar etiquetas o marcas en un texto que indique como debe verse, es decir es un sistema de etiquetas. Para nuestro proyecto se utilizará combinándolo con php para mejorar el diseño y desarrollo de las interfaces gráficas.

Notepad++. Es un editor de texto y editor de código fuente, se ocupará para desarrollar los códigos en php de los módulos que contemplará nuestro sitio web, puede programar en varios lenguajes tales como: html, css, javascript, php.

Javascript. Es un lenguaje de programación interpretado, será ocupado para realizar mejoras en las interfaces gráficas de nuestro sitio web y los formularios. Con este lenguaje y un plugin fpdf se podrán implementar documentos pdf que ocupará nuestro sitio web.

WOW Slider: Hace que sea muy fácil agregar una presentación de diapositivas a una página web html existente. Hay dos métodos para su uso. El primer método no requiere ningún conocimiento de html y hace que todo el proceso sea extremadamente simple.
El segundo método funciona si se siente cómodo trabajando con html y quiere tener más control sobre la página final.

Xamarin: Es una plataforma para desarrollar aplicaciones para plataformas iOS, Android, Windows Phone, Windows Store y Mac usando el lenguaje de programación C\#, este plugin se utilizará junto con visual studio para desarrollar nuestra aplicación móvil.

Visual Studio: Es un conjunto completo de herramientas de desarrollo para la generación de aplicaciones web asp.net, servicios web xml, aplicaciones de escritorio y aplicaciones móviles. visual basic, visual c\# y visual c++ utilizan todo el mismo entorno de desarrollo integrado (ide), que habilita el uso compartido de herramientas y facilita la creación de soluciones en varios lenguajes.

\section{Tipo de investigación}

En el proyecto colaboraron dos alumnas de la carrera de ingeniería en tecnologías de la información, un asesor de estadías y del lado del inifap el Dr. David Heriberto Noriega Cantú, dicho trabajo se conceptualiza como bien lo escribe el Dr. Arturo A. Pacheco Espejel en su libro titulado Metodología Crítica de la investigación, lógica, procedimientos y técnicas que a la letra dice: que "la investigación tecnológica es la que se encarga de desarrollar un conocimiento enfocado a diseñar o mejorar los instrumentos y las herramientas que el hombre necesita para potenciar su fuerza de trabajo y sus capacidades transformadoras de la realidad" ${ }^{\prime 10]}$.

Con lo anterior se puede comprender que el sitio web y la aplicación móvil serán herramientas que facilitarán la construcción del paquete tecnológico de fertilización y conocer más acerca de los terrenos de siembra, tal como: clima, tipo de suelo, áreas agrícolas, entre otros rubros de información.

Para realizar el presente trabajo entre el inifap y la universidad tecnológica, se probó y revisó un programa que calcula el paquete tecnológico de fertilización para terrenos de siembra de maíz en el estado de morelos, dicho software se denomina sistema de fertilización para el estado de morelos ${ }^{[7]}$, contiene información limitada en el registro censal y no se puede actualizar dicha herramienta. 


\section{Metodología de desarrollo de software}

El software se ha convertido en el elemento clave de la evolución de los sistemas y productos basados en computadoras, así como en una de las tecnologías más importantes en el ámbito mundial. En la actualidad el software evoluciona de acuerdo con un conjunto de leyes que han permanecido inalteradas a lo largo de 30 años. La intención de la ingeniería de software es proporcionar un marco general para construir software con una calidad mucho mayor ${ }^{[11]}$.

A continuación, se muestra la metodología que se utilizará para concluir el proyecto y se ofrece una breve descripción en cada una de estas actividades y tareas:

\begin{tabular}{|c|c|}
\hline Etapa & Descripción \\
\hline $\begin{array}{l}\text { Recopilación de la } \\
\text { Información }\end{array}$ & $\begin{array}{l}\text { En esta etapa, se adecuarán entre } \\
\text { otros los procesos de inicio de } \\
\text { sesion para los usuarios y mejorar } \\
\text { el acceso al sitio web y creación } \\
\text { de una aplicación móvil. }\end{array}$ \\
\hline Análisis & $\begin{array}{l}\text { En esta etapa se retomarán los } \\
\text { trabajos para mejorar la } \\
\text { información que se captura de los } \\
\text { terrenos de siembra de maíz, } \\
\text { cálculo del paquete tecnológico y } \\
\text { detalles en las consultas para } \\
\text { generar un reporte general de } \\
\text { productores de maíz. }\end{array}$ \\
\hline $\begin{array}{ll}\text { Diseño } & y \\
\text { codificación } & \end{array}$ & $\begin{array}{l}\text { Aquí se recodificarán algunos } \\
\text { algoritmos y se rediseñarán las } \\
\text { interfaces graficas de usuario para } \\
\text { mejorar el manejo del sitio web, } \\
\text { asi mismo se modelará y } \\
\text { construirá la aplicación móvil en } \\
\text { xamarin para android en visual } \\
\text { studio } 2017 \text {. }\end{array}$ \\
\hline Implementación & $\begin{array}{l}\text { Se reimplementará el sitio web } \\
\text { para que pase de la fase de acceso } \\
\text { local a acceso remoto a través de } \\
\text { un hosting contratado para ello, el } \\
\text { cual es un subdominio llamado } \\
\text { dotacionfertilizante.opds. website, } \\
\text { incluyendo la aplicación móvil. }\end{array}$ \\
\hline Pruebas & $\begin{array}{l}\text { Las pruebas se llevarán al cabo } \\
\text { una vez alojado el sitio web en el } \\
\text { hosting asi como también con la } \\
\text { aplicación móvil en una app store, } \\
\text { para verificar su funcionalidad y } \\
\text { corregir los posibles errores que } \\
\text { puedan tener. }\end{array}$ \\
\hline Documentación & $\begin{array}{l}\text { Aquí se realizará la actualización } \\
\text { de la documentación que } \\
\text { acompañará al sitio web y la } \\
\text { aplicación móvil que sirva de } \\
\text { apoyo para su mejor } \\
\text { comprensión. }\end{array}$ \\
\hline
\end{tabular}

Tabla 1 Etapas de la metodología de desarrollo de software

\section{Conclusiones}

\section{Del sitio web:}

- Se actualizó la base de datos inifapbd según fuera necesario en las tablas que lo requirieran a través de mysql.

Se readecuó el nivel de seguridad a través de roles de administrador y usuario.

Se utilizaron las herramientas web, tales como: php, javascript, html5 y xampp para construir el sitio.

- Se generó información específica sobre la fuente y dosis de fertilizante para cada municipio y localidad de la región norte de guerrero, tomándose solo unas muestras en iguala, tepecoa y cocula.

Se construyó el reporte de fertilización para los productores de maíz a través de un documento en formato pdf para consulta e impresión.

- Se contrató el dominio opds.website para alojar el sitio web creando un subdominio llamado dotacionfertilizante.opds.website.

\section{De la aplicación móvil:}

- $\quad$ Se utilizó el lenguaje de programación C\#, xaml y xamarin forms para android en el diseño y codificación junto a visual studio 2017.

- Se construyó la aplicación móvil adecuada a la estructura del sitio web, con base en un menú y brindando información a los productores de maíz, de los municipios de la región norte del estado de guerrero.

- No ha sido posible conectar el sitio web con la aplicación móvil a través de un api restful service (microservicio) para el acceso remoto entre ambas plataformas. 


\section{Resultados}

\section{Del sitio web:}

En la figura 1, se puede apreciar el menú principal del sitio web que contiene tres opciones, tales como: Iniciar Sesión, Registro, Video.

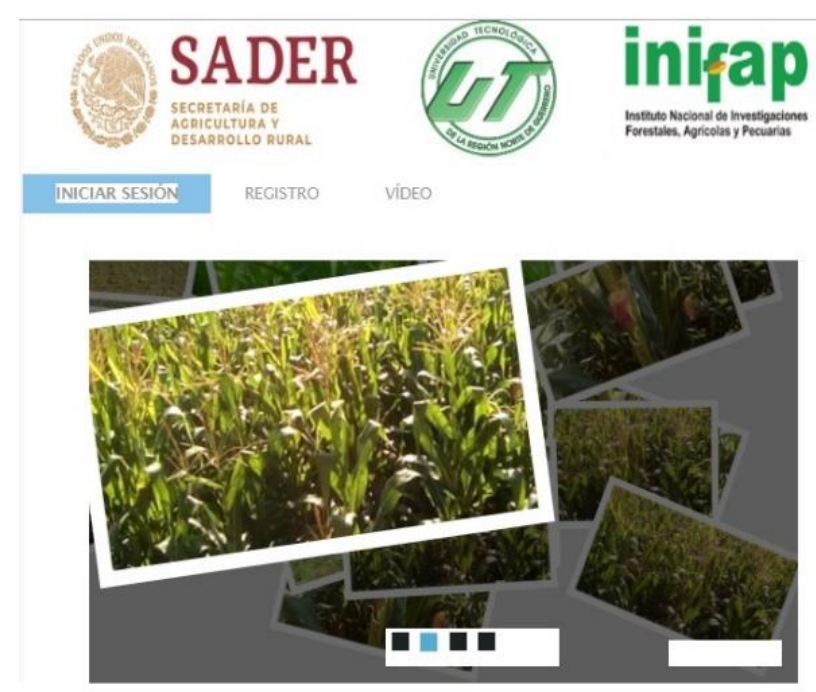

Figura 1 Vista principal del sitio web

En el caso de que el usuario ya se encuentre registrado sea con el rol de administrador o no, el sitio web le ofrece la opción de iniciar sesión para que capture su nombre de usuario y contraseña, tal como se muestra en la figura 2.

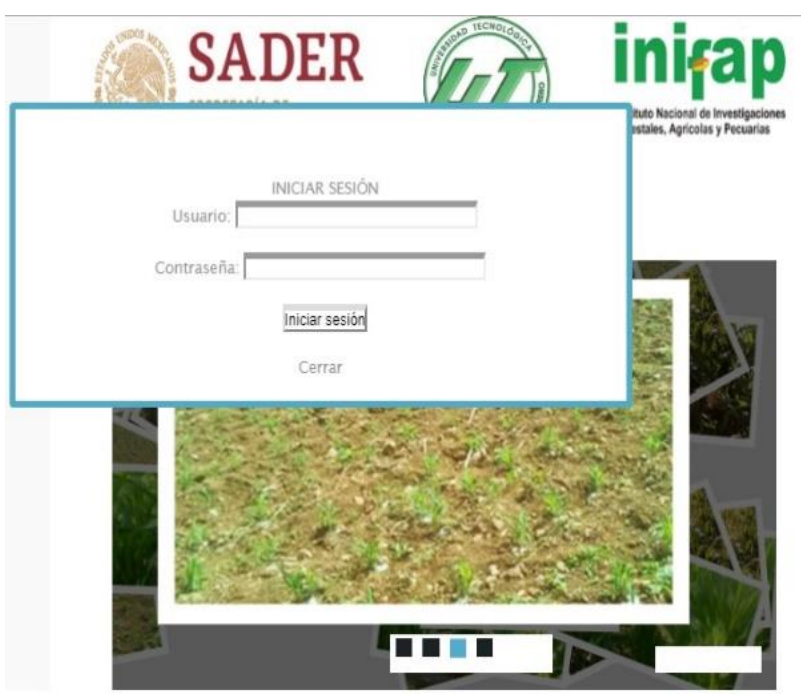

Figura 2 Vista iniciar sesión de usuario

De otra forma, el usuario tendrá que registrarse con la información que se le pide capturar por primera vez para que pueda acceder posteriormente según sea el caso como usuario común o administrador. Tal como se observa en la figura 3.

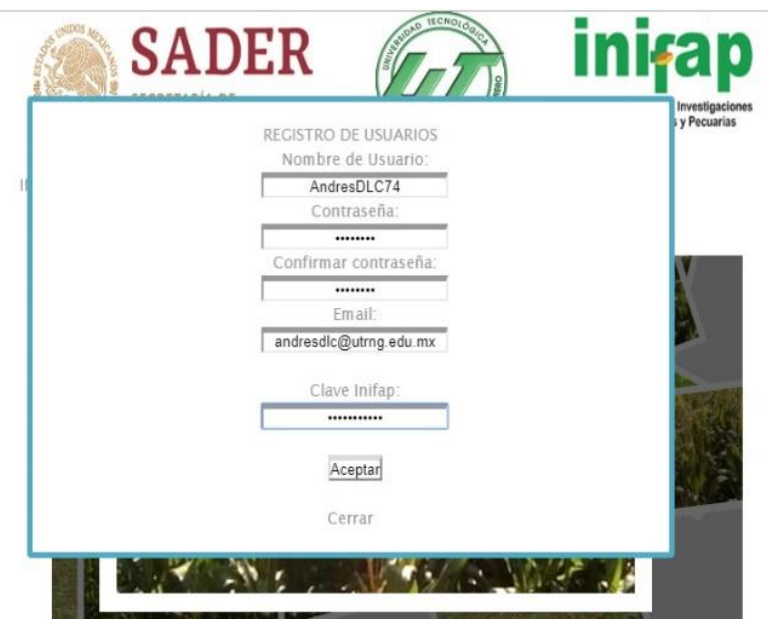

Figura 3 Vista registro de usuarios

Una vez que se autentifica el usuario y este no es un usuario administrador, el sitio web muestra un menú con opciones, tales como: Inicio, ¿Quiénes Somos?, Contactos, Calcular Tratamiento, Cerrar Sesión, tal como se muestra en la figura 4 , el propósito de este menú es que solo realice consultas de la información y no sea modificable por ningún motivo.

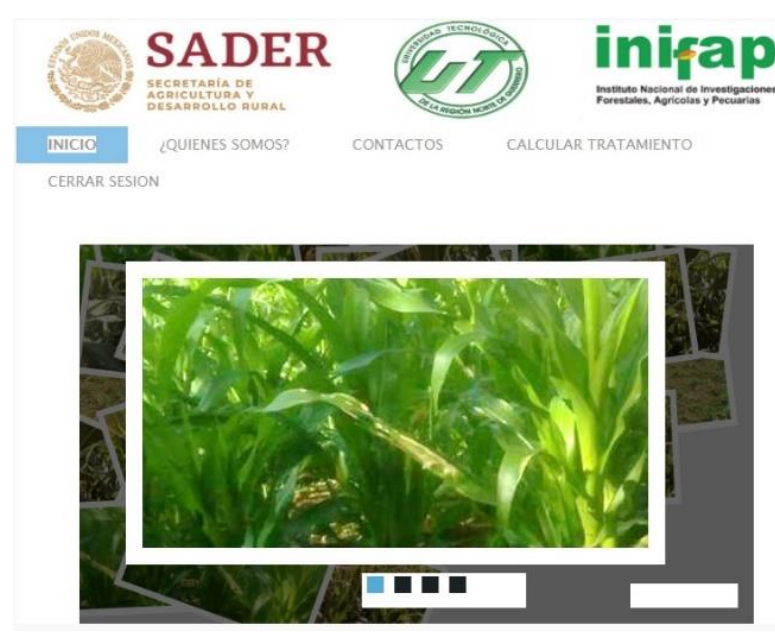

Figura 4 Vista usuario no administrador

A continuación, se explicarán las vistas que le presenta el sitio web a un usuario común, tal como se observa en la figura 5 , donde se puede apreciar información sobre que es el inifap como centro de investigación para el sector agrícola, cual es la misión como tal, que visión contempla y el mandato con que cuenta. 


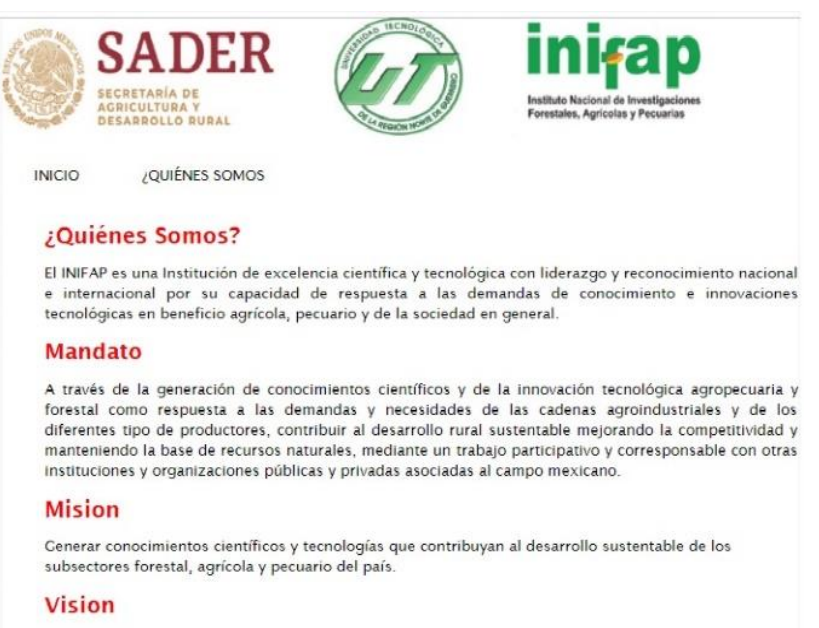

Figura 5 Opción ¿Quiénes Somos?

En la figura 6, se muestra información sobre investigadores con los que el usuario pueda comunicarse, ya sea por medio telefónico usando las extensiones o bien por correo electrónico, con el propósito de desarrollar un proyecto.

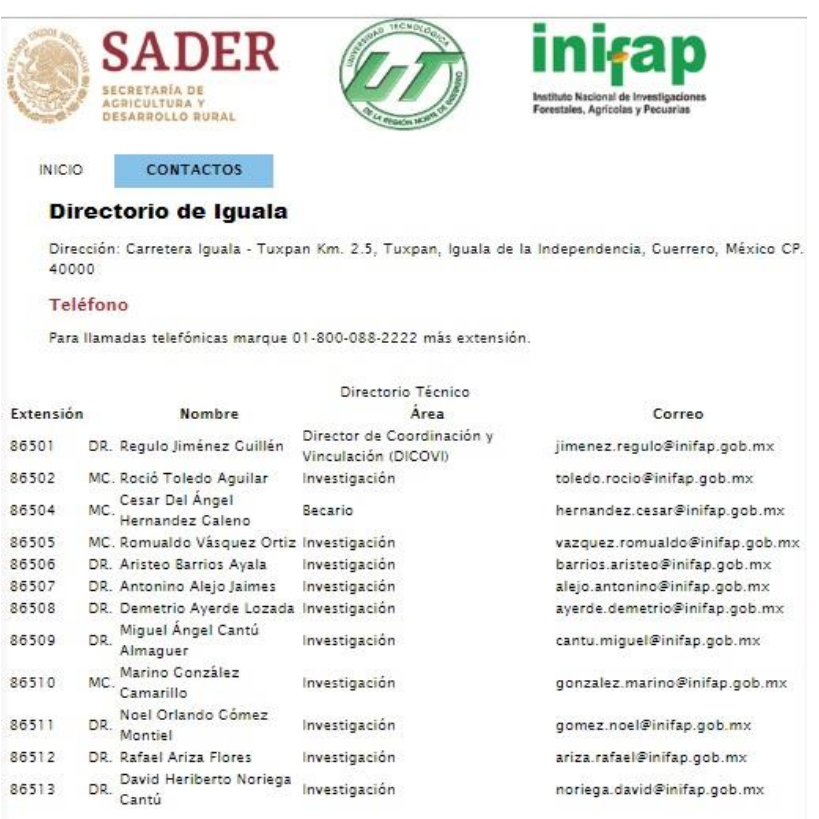

Figura 6 Vista contactos

En caso de que el usuario seleccione la opción calcular tratamiento, se mostrará una vista con el mapa del estado de guerrero, tal como se observa en la figura 7 , donde se permite seleccionar de una lista la localidad, nombre del propietario, y capturar el número de hectáreas, después hacer clic en el botón calcular tratamiento para que se obtenga el paquete tecnológico de fertilizante.

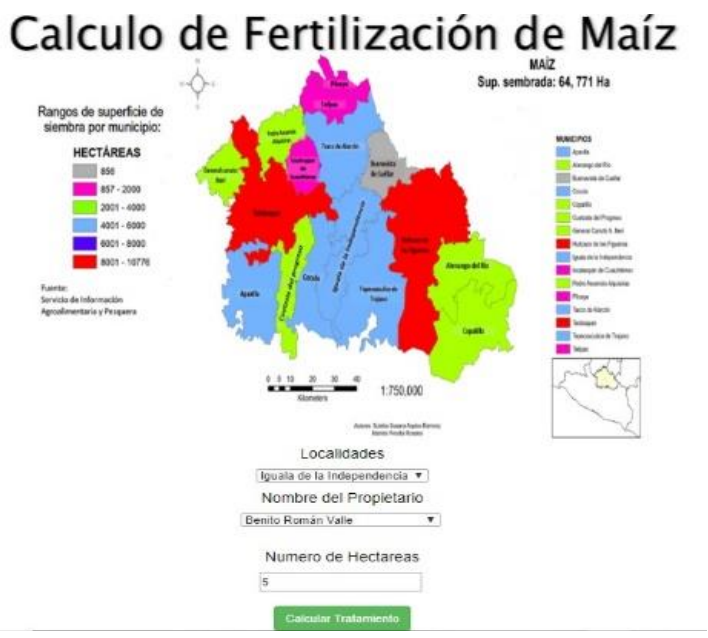

Figura 7 Vista del mapa de guerrero por rangos de superficie de siembra de maíz por municipio y hectáreas para el usuario común

Una vez que se realiza el proceso del cálculo de fertilización, se muestra la siguiente información, tal como se observa en la figura 8 , cabe mencionar que dicha información está limitada ya que esta solo se presenta a un usuario no administrador.

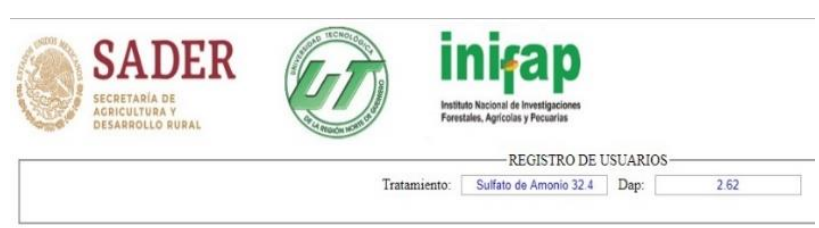

Figura 8 Resultado del cálculo del paquete tecnológico de fertilización

En caso de que el usuario se autentifique como usuario administrador, la vista del menú principal será como se observa en la figura 9, donde las opciones del menú son: inicio, propietario, características físicas, composición química, uso del suelo, cultivos, mapa, lista y cerrar sesión.

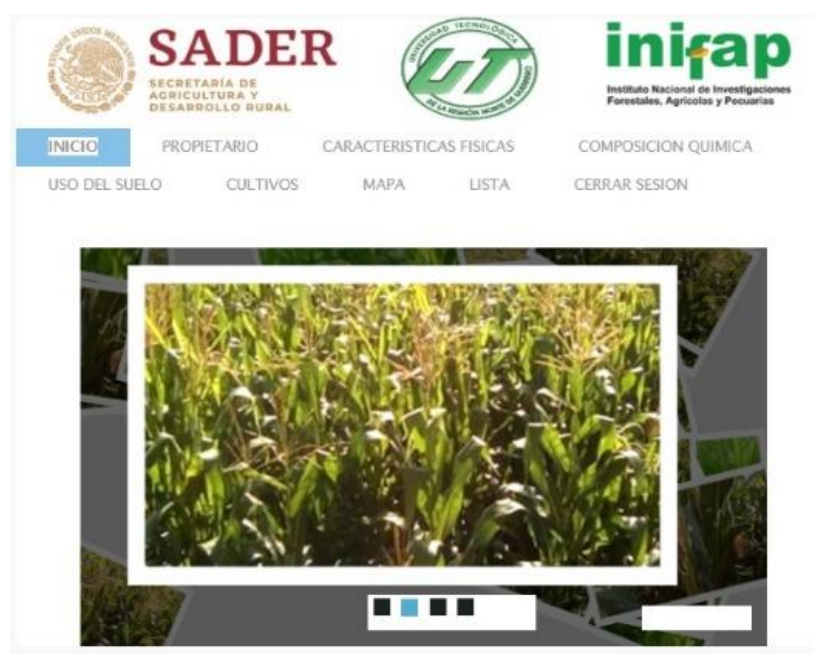

Figura 9 Vista del menú principal como usuario administrador

DE LEÓN-CASTREJÓN, Andrés, OCHOA-LÓPEZ, Ana Laura, NORIEGA-CANTÚ, David Heriberto y SALGADO MORA, Gabriela. Sitio web y aplicación móvil de control de uso del suelo a través del mapa interactivo de la región norte del estado de Guerrero, segunda fase. Revista de Simulación Computacional. 2019 
En la opción de propietario se captura información del propietario del terreno de siembra, tal como se observa en la figura 10 , dichos datos son: nombre, apellido paterno, apellido materno, campo, ddr, latitud, longitud, municipio y localidad. Una vez verificados los datos se hace clic en el botón registrar.

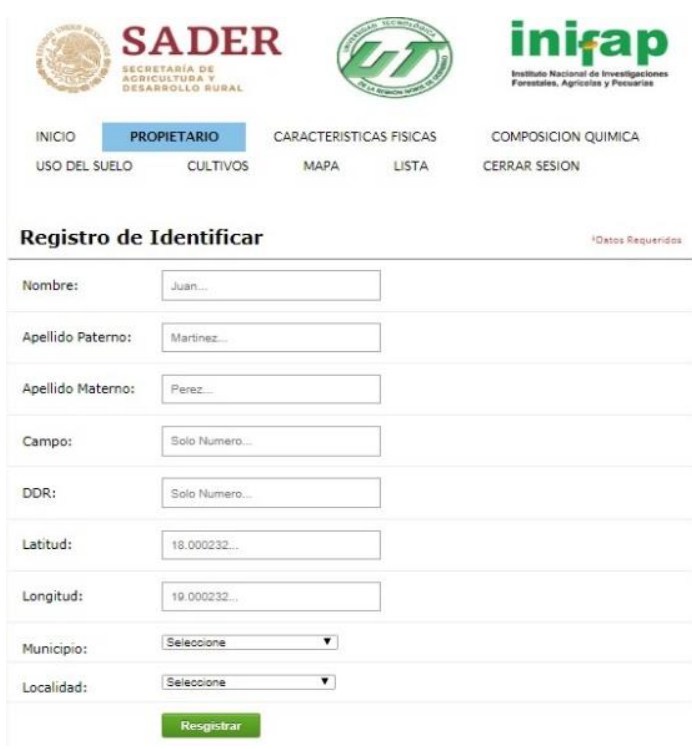

Figura 10 Formulario de datos del propietario

En la opción características físicas, se capturan los datos físicos del terreno de siembra, tal como se observa en la figura 11, y finalmente se relaciona con el propietario del mismo.

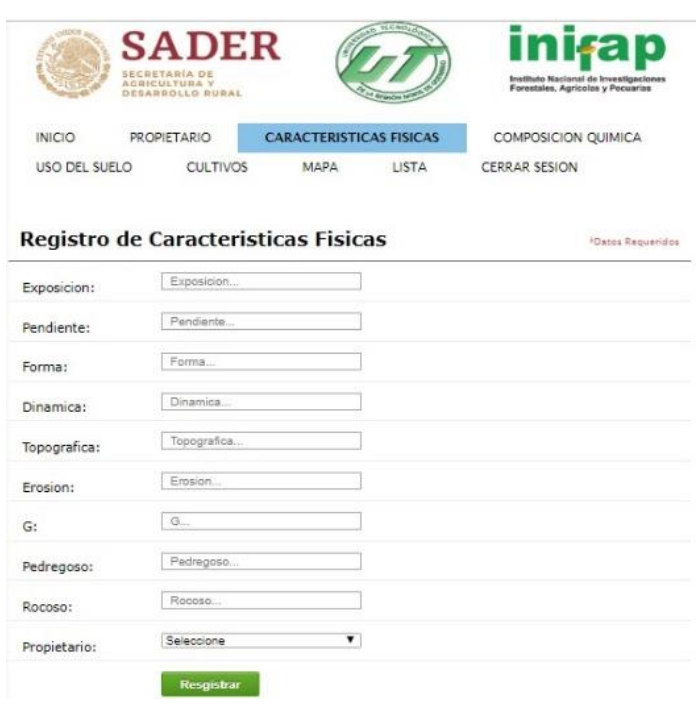

Figura 11 Formulario características físicas

En la opción de composición química del terreno se puede apreciar los datos a capturar por el usuario administrador para que al final se relacionen también con el propietario, de forma similar que, en la opción anterior, tal como se observa en la figura 12.

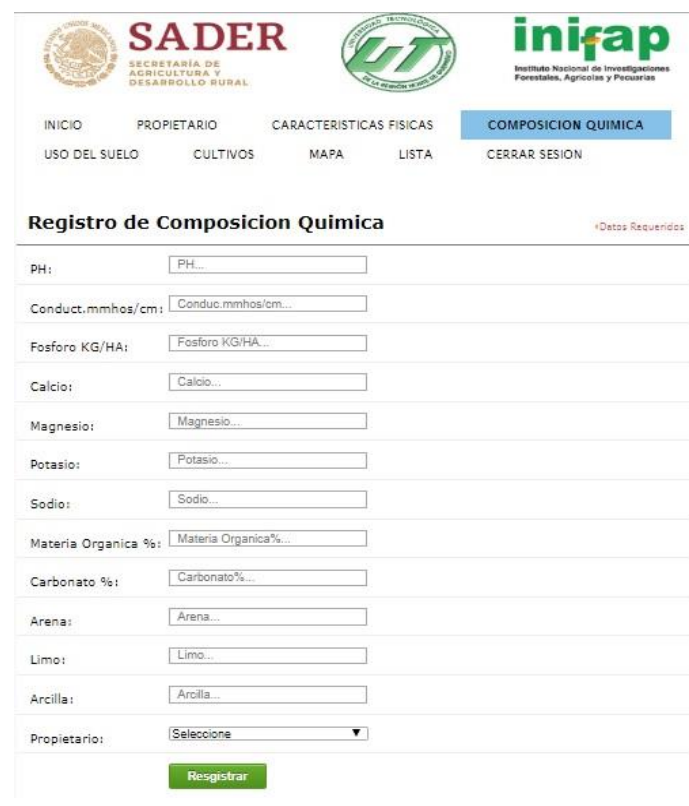

Figura 12 Formulario composición química

En la opción de uso de suelo, se capturan datos que servirán como parte del censo agrícola, tal como se observa en la figura 13, y de forma similar al formulario anterior se relaciona con el propietario del terreno de siembra.

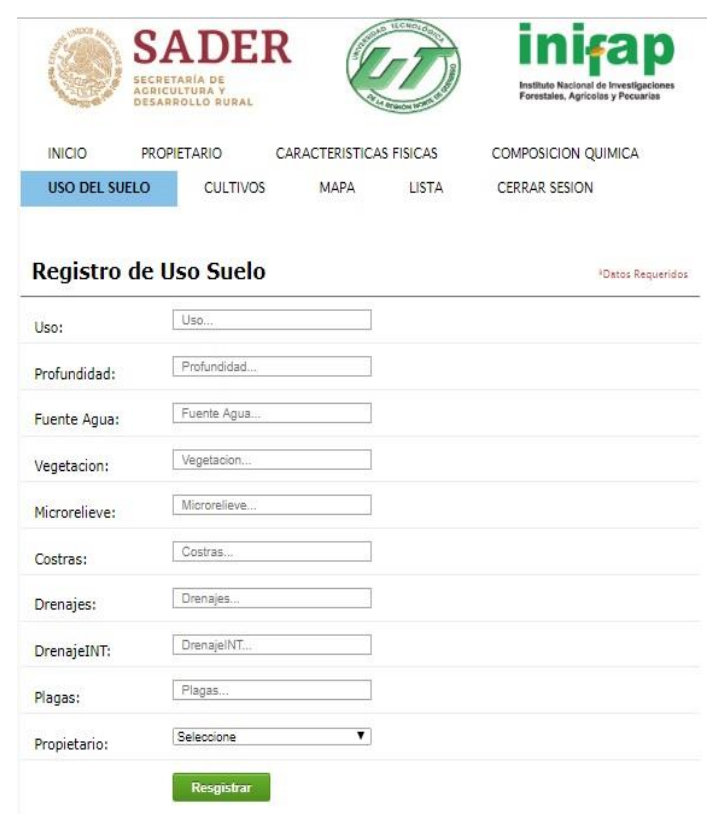

Figura 13 Formulario uso del suelo

En la opción de cultivos, tal como se observa en la figura 14, se capturan datos del tipo de cultivo que tendrá el terreno de siembra, con el propósito de realizar el cálculo del paquete tecnológico de fertilizante según corresponda y así mismo se relaciona con el propietario del terreno. 


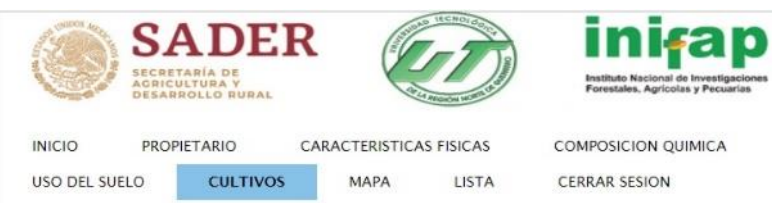

Registro de Cultivo -Daros Requeridos

Tipo de Cultivo: Tipocullivo.

variedad:
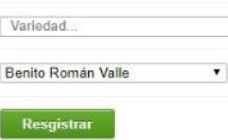

Figura 14 Formulario cultivos

En la opción del mapa, se muestra el mapa de la república mexicana en donde se selecciona el estado de guerrero, después se elige la región a la que pertenece el terreno de siembra, tal como se observa en la figura $15 \mathrm{y}$ 16.
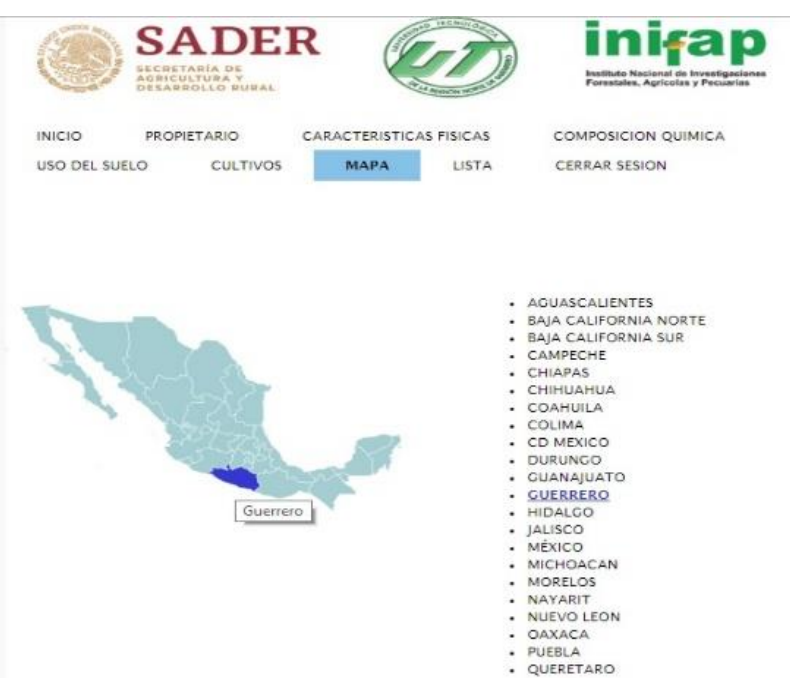

Figura 15 Mapa de la república mexicana

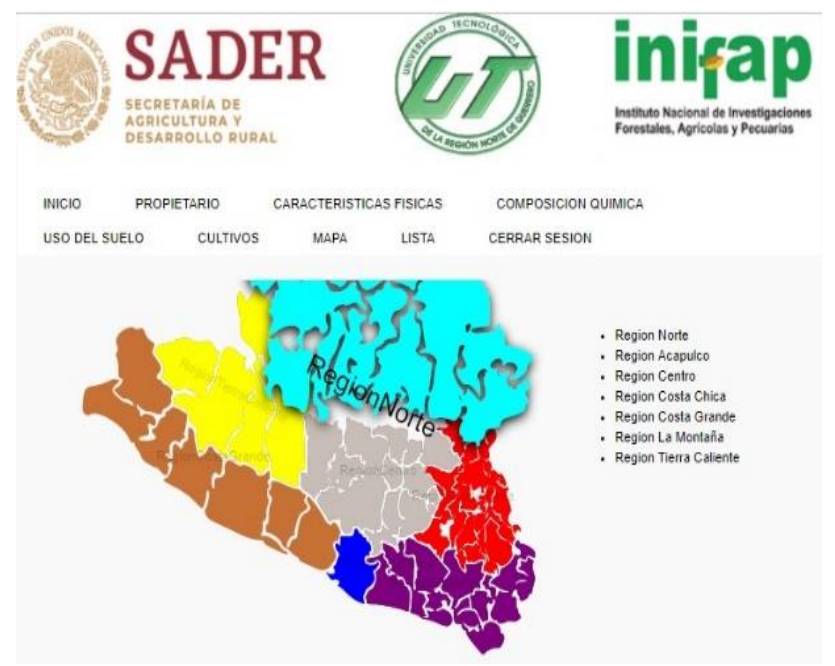

Figura 16 Mapa del estado de guerrero por regiones
Posteriormente, se elige el municipio y localidad en donde se encuentra ubicado el terreno de siembra del propietario al cual se le realizará el cálculo del paquete tecnológico de fertilización, tal como se observa en la figura 17 , que para nuestro ejemplo es del municipio y localidad de iguala de la independencia.

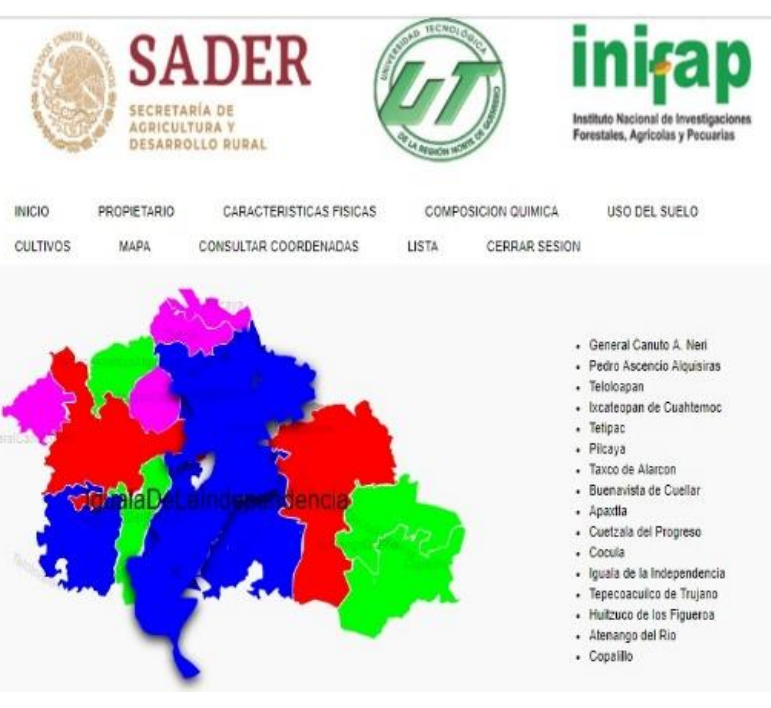

Figura 17 Vista del mapa por municipios y localidades

Una vez elegido el municipio, se selecciona la localidad donde se ubica el terreno de siembra, después se escoge de una lista el nombre del propietario, y se captura el número de hectáreas que tiene para sembrar, tal como se observa en la figura 18 , y finalmente se hace clic en el botón calcular tratamiento.

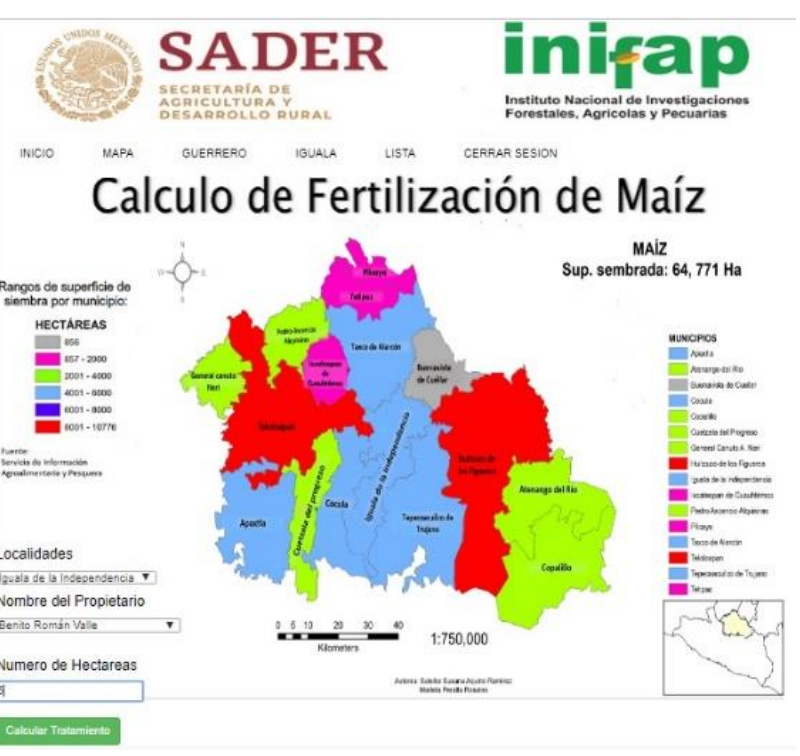

Figura 18 Vista del mapa de guerrero por rangos de superficie de siembra de maíz por municipio y hectáreas para el usuario administrador 
Posterior a eso, se mostrará en otra vista el resultado que se obtenga de acuerdo con el ph del terreno la dosis en bultos por $\mathrm{kg}$ y el tipo de fertilizante a ocupar en ellos, de acuerdo con el tipo de tratamiento 90-60-00 que aplica el inifap para ello (ver anexo de tablas) ${ }^{[8]}$, tal como se observa en la figura 19.

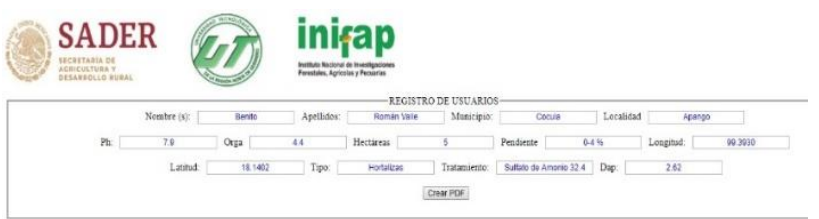

Figura 19 Resultado del cálculo del paquete tecnológico de fertilización

En el caso de que el usuario elija crear una vista en pdf del resultado para su impresión se hace clic en el botón crear pdf y se construirá dicha vista en pdf, tal como se observa en la figura 20.

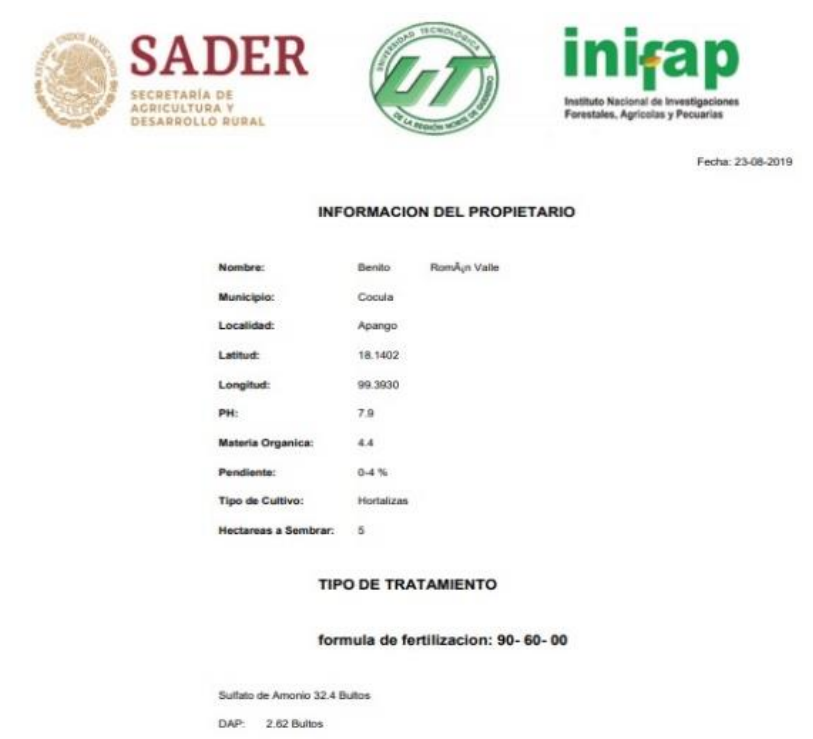

Figura 20 Resultado del cálculo del paquete tecnológico de fertilización en vista pdf para su impresión

En la opción de consultar coordenadas en el mapa, tal como se observa en la figura 21 , en esta se realiza la ubicación de los terrenos de siembra de acuerdo con su latitud y longitud geográfica, en esta vista se aplica el alta del terreno en dichas coordenadas de latitud y longitud o su eliminación según sea el caso y así mantener actualizados estos dos datos.

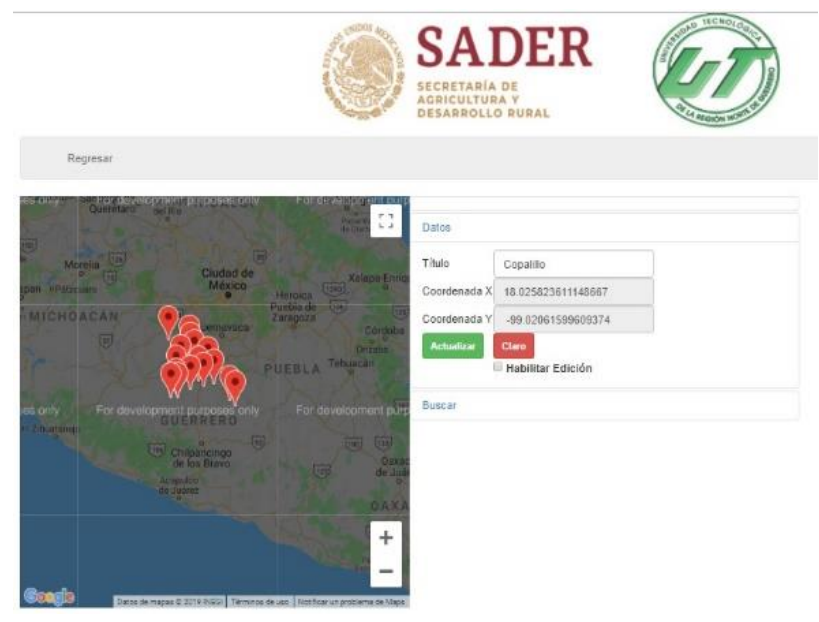

Figura 21 Actualización de los terrenos, según su latitud y longitud

Si se elige la opción de lista, se mostrará un reporte general de todos los propietarios de terrenos de siembra de hortalizas que contiene el censo agrícola, obteniéndose en formato web y pdf según se requiera, tal como se observa en las figuras 22 y 23, asi en caso de que se necesite saber la información de un solo propietario se escribe en la caja de texto a la izquierda de la lista, el nombre del propietario y también se mostrará de forma individual en vista web o pdf.

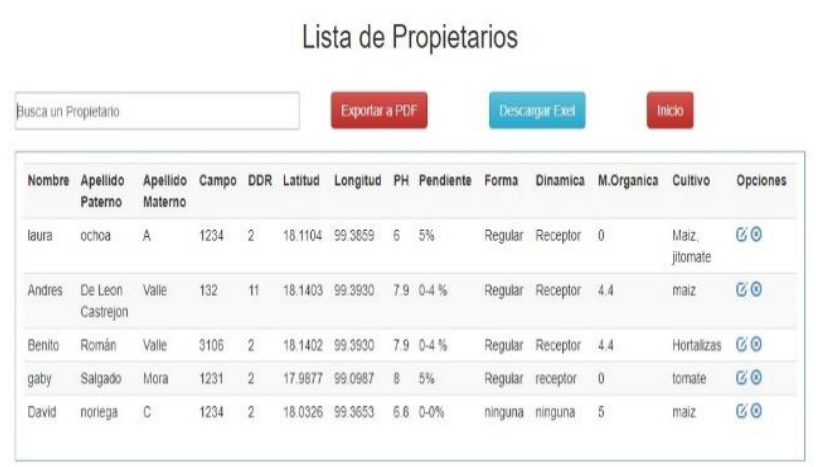

Figura 22 Vista web de la lista de propietarios de los terrenos de siembra

Fecha 230602019

LISTADO DE PROPETARIOS

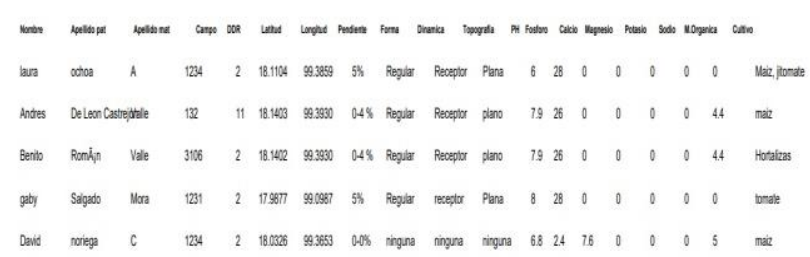

Figura 23 Vista pdf de la lista de propietarios de los terrenos de siembra 
En la opción de cerrar sesión, funcionará en ambos casos, es decir sea que se haya autentificado como usuario común o usuario administrador, se finaliza el sitio web y envía un mensaje de que se ha cerrado exitosamente la sesión de usuario, tal como se observa en la figura 24.

\section{dotacionfertilizante.opds.website dice}

Cerraste Sesion...

Figura 24 Vista ventana cerrar sesión

\section{De la aplicación móvil}

Con respecto de la aplicación móvil, aquí solo se ha realizado la estructura de las interfaces gráficas de usuario debido a la falta de tiempo para realizar el acceso remoto a través de un api restful (microservicio), tales como: login, inicio, acerca, ¿quiénes somos?, menú principal en dos vistas, registrarse, propietarios, calcular tratamiento, directorio y contacto.

Por ello solo se tratará de explicar a través de un ejemplo ficticio el cómo funcionará la aplicación móvil ya una vez que sea terminada.

Una vez que a la aplicación móvil se le implemente el api restful como microservicio para que conecte de forma remota a la base de datos del sitio web y pasando el proceso de pruebas tendrá las siguientes interfaces graficas:

Se cargará una pantalla de logeo inicial, tal como se observa en la figura 25 , en caso de que ya se haya registrado con anterioridad para que autentifique sus datos y acceda al menú principal o bien si es el caso por primera vez se registre como usuario nuevo, tal como se observa en la figura 26.

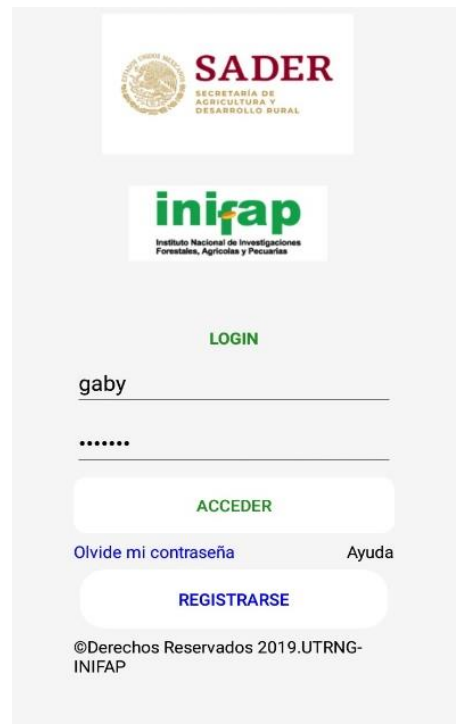

Figura 25 Vista login.

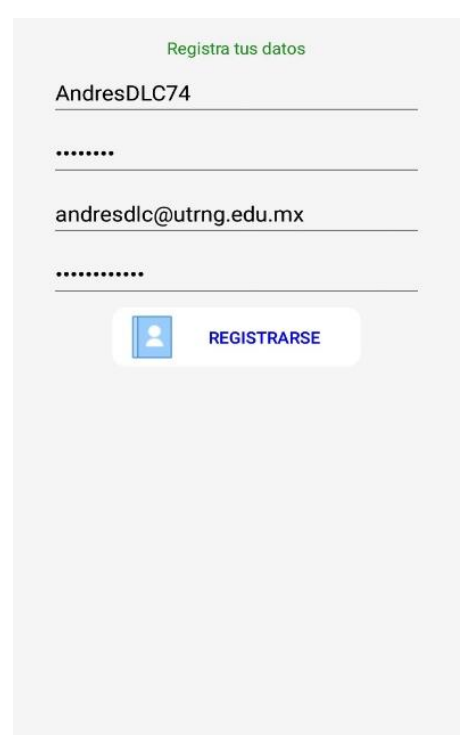

Figura 26 Vista Registrarse

En ambos casos, será un usuario común y no administrador, ya autentificados los datos usuario y contraseña se mostrarán dos vistas del menú principal ya sea utilizando como una página dentro del grupo de páginas de la aplicación o bien utilizando el botón de menú ubicado en la esquina superior izquierda de la misma. Tal como se observa en las figuras $27 \mathrm{y}$ 28 respectivamente. 


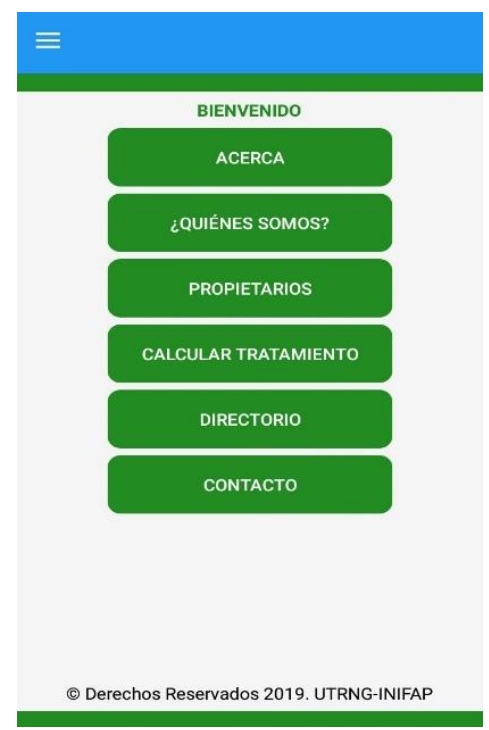

Figura 27 Vista menú principal dentro del grupo de páginas

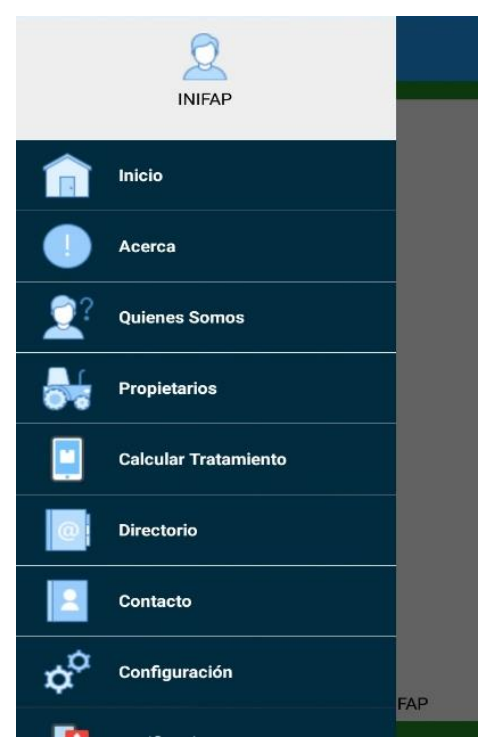

Figura 28 Vista menú principal del botón de menú

Ahora bien, el acceso a las opciones de cualquiera de los dos menús funcionará exactamente igual.

Si se da un toque en la opción Acerca..., la aplicación enviará una pantalla que mostrará información del inifap, tal como se observa en la figura 29. En el caso de dar un toque en ¿Quiénes somos?, se enviará a una pantalla que muestre información de que hace el inifap como centro de investigación, la misión, visión, mandato entre otra información que también contiene el sitio web, tal como se observa en la figura 30.

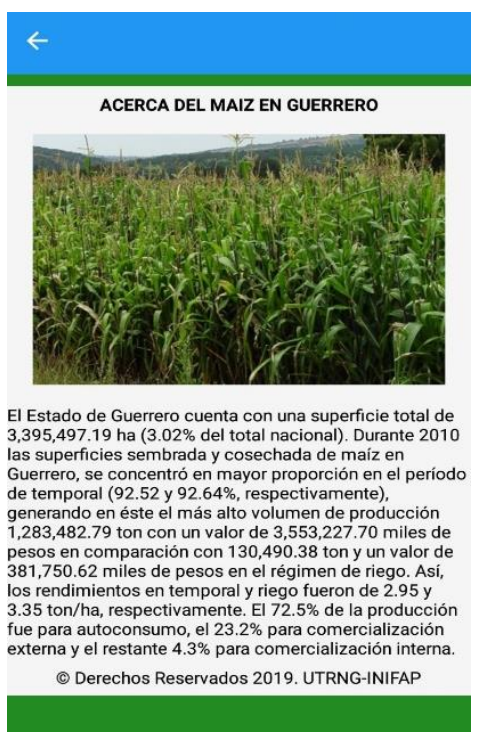

Figura 29 Vista acerca de

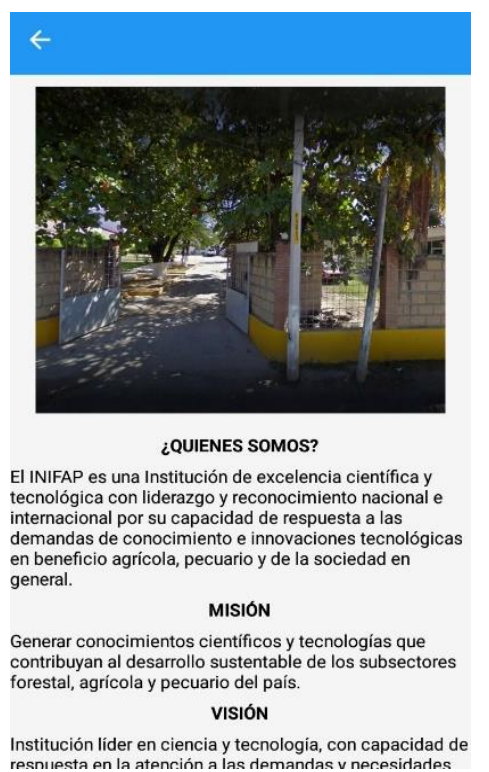

Figura 30 Vista ¿Quiénes somos?

En la opción propietarios se mostrará una pantalla, tal como se observa en la figura 31, para realizar la búsqueda de algún propietario ya registrado, si se encuentra en el sitio web, este regresará un registro con información, tal como se observa en la figura 32, caso contrario no se mostrará ningún registro. 


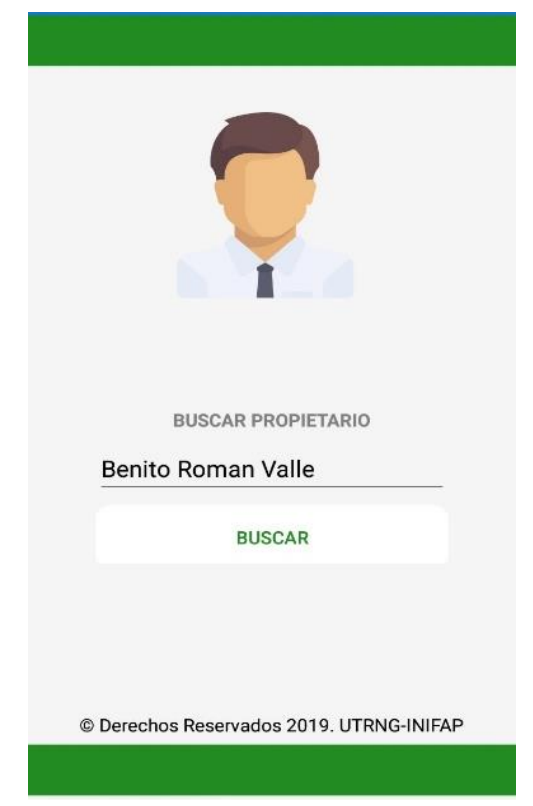

Figura 31 Vista Buscar propietario

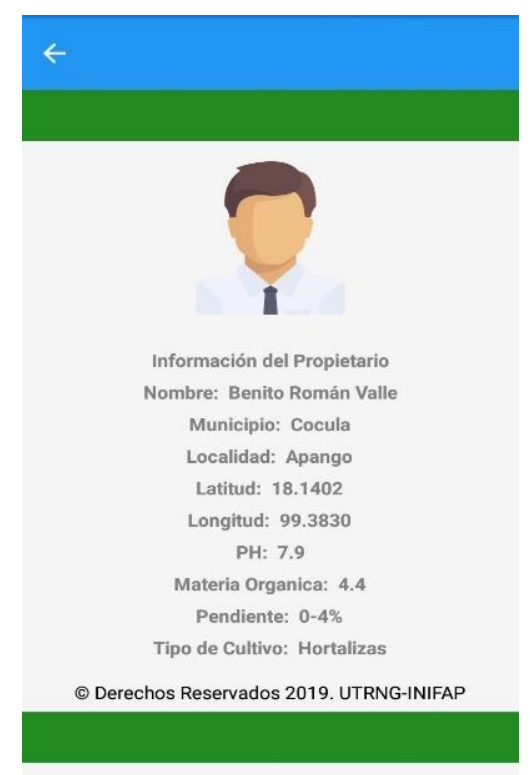

Figura 32 Vista información del propietario registrado

En caso de dar un toque en la opción de calcular tratamiento, se mostrará una pantalla para capturar la información del propietario y del terreno de siembra, junto al ph del suelo, características físicas y composición química del mismo, tal como se observa en las figuras $33 \mathrm{y}$ 34 respectivamente.
Septiembre, 2019 Vol.3 No.9 1-16

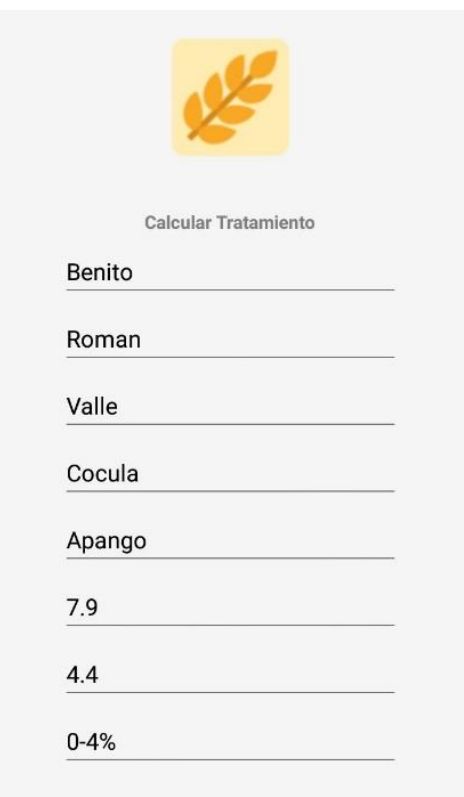

Figura 33 Vista 1 captura de datos para obtener dosis de fertilizante

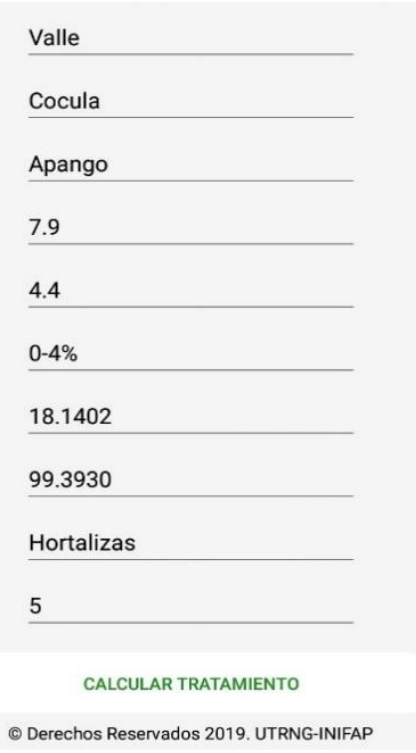

Figura 34 Vista 2 captura de datos para obtener dosis de fertilizante

Una vez finalizada la captura de datos del propietario y algunos datos del terreno de su propiedad, y si no existiese algún dato con errores, se da un toque en el botón calcular tratamiento para obtener la dosis de fertilizante a ocupar para la siembra del maíz, tal como se observa en la figura 35 .

Cabe mencionar que este proceso es exactamente el mismo que se encuentra en el sitio web y de acuerdo con la fórmula de tratamiento 90-60-00 que aplica el inifap (ver anexo de tablas $)^{[8]}$. 


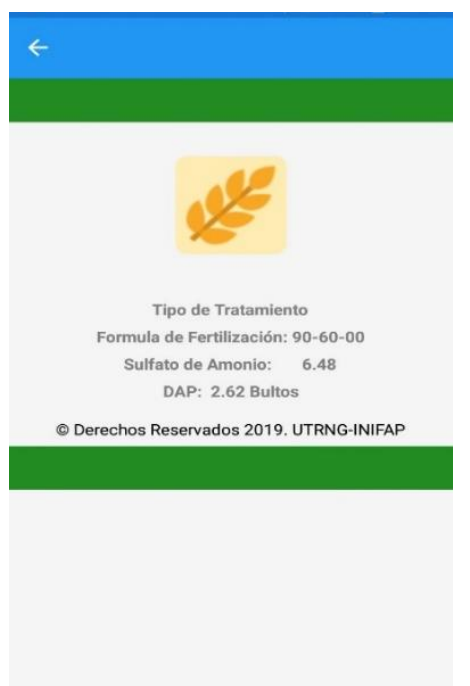

Figura 35 Vista Resultado del tratamiento de fertilización

En el caso de dar un toque en la opción directorio, se mostrará información de los investigadores que están trabajando en el inifap, tal como se observa en la figura 36 , y si se elige la opción contactos, se mostrará información de los medios a través de los cuales se puede establecer comunicación con los investigadores para realizar proyectos con ellos. Tales medios son: el teléfono con varias extensiones y el email del instituto o bien de cada investigador.

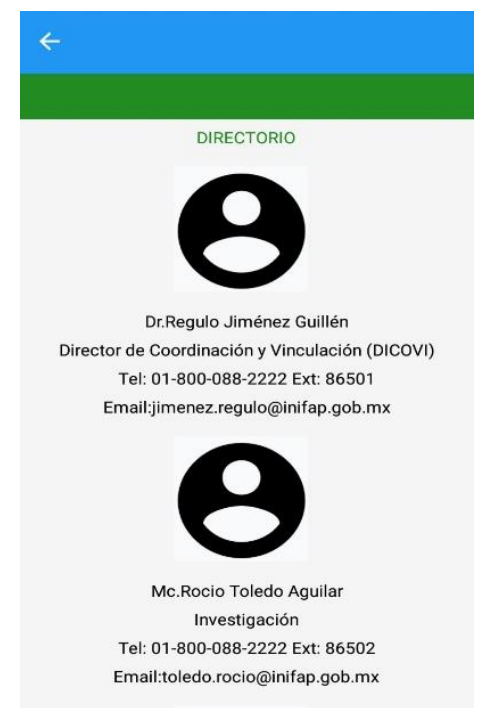

Figura 36 Vista directorio

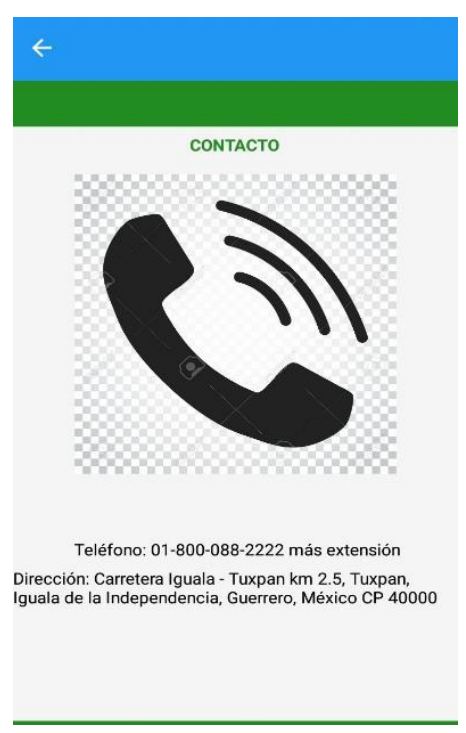

Figura 37 Vista contactos

\section{Trabajos futuros}

Actualizar los registros de los terrenos de siembra y sus propietarios para cubrir al $100 \%$ el censo agrícola.

Capturar la información de los propietarios de terrenos de siembra que se encuentran en las demás regiones del estado de guerrero.

- Construir y agregar módulos en el sitio web para que abarque otros tipos cultivos, tales como: jamaica, cacahuate, sorgo, etc.

- Realizar otro censo agrícola con el propósito de actualizar el padrón que se tiene registrado hasta la fecha, ya que el que se tiene es un catálogo que data desde el año 1998.

- Dotar a la aplicación móvil de un api restful (microservicio) con acceso remoto al sitio web, de manera que los investigadores puedan contar con información de primera mano.

\section{Referencias}

[1].Barrientos Avendaño, E., Rico Bautista, D., Coronel Rojas, L., \& Cuesta Quintero, F. (2019). Jardín botánico: Prototipo de software para la gestión y divulgación de plantas nativas basado en código $Q R$ y realidad aumentada. Revista Ibérica de Sistemas y Tecnologías de Información, 267-282. 
[2]. Contreras Moreras, S. J. (2019). Los trabajos prácticos como estrategia pedagógica para la enseñanza aprendizaje del concepto páramo a través del frailejon (asteraceae: espeletia) con estudiantes de grado noveno (901) en la Escuela Normal Superior Distrital María Montessori.

[3].Cruz M., L. E., Gaytán, J. F., de Jesús Navarrete, A., Jiménez, T. C., Gamboa, J. A., Valle, N. T., \& Díaz López, H. O. (s.f.). Dr. Mario González Espinosa Director General.

[4].De León Castrejón, A., Hernández Martínez, A. J., Fernández Victoria, J. R., De León Castrejón, V., \& Noriega Cantú, D. H. (2017). Website and mobile application on land use control through the interactive map of the northern region of the state of guerrero for inifap. Ecorfan Democratic Republic of Congo, 27-33.

[5].Escalante, S., \& Tercero, J. L. (2019). Mejoramiento del cultivo del tomate por medio de un sistema electrónico automático (SEA), para el control de riego por goteo en el distrito de Lamas.

[6].Flórez, L. D., Naranjo, R., Balcázar Daza, A. M., \& García Norato, O. M. (2019). Competitividad y Desarrollo Regional en Colombia.

[7].INIFAP, C. E. (2006). Sistema de Fertilización para el Estado de Morelos. Cuernavaca, Morelos, México.

[8].INIFAP, C. E. (2016). Paquete Tecnológico para Maíz de Temporal. Ciclo Agrícola Primavera - Verano. Iguala de la Independencia, Gro.

[9].Instituto Nacional de Investigaciones Forestales, A. y. (2015). INIFAP, Campo Experimental Iguala. Obtenido de http://www.inifap.gob.mx/SitePge/inifap20 15/Quienes_Somos/quienes_somos.aspx

[10]. Pacheco Espejel, A., \& Cruz, E. M. (2008). Metodología Crítica de la Investigación, Lógica, Procedimiento y Técnicas. Mexico: Grupo Editorial Patria.

[11]. Pressman Roger, S. (2005). Ingeniería de Software, Un Enfoque Práctico, Sexta Edición. México: Mc Graw-Hill.

\section{Anexos}

En este punto, se anexan como referencia las tablas del tipo de tratamiento con la fórmula 9060-00 del inifap, que se establecieron para realizar la construcción del paquete tecnológico de fertilización a aplicar en cada terreno de siembra ${ }^{[8]}$. 
Paquete Tecnológico para maíz de temporal, ciclo agrícola primavera - verano $^{[8]}$

\section{Estado: Guerrero.}

Nivel de Potencial Productivo: Alto

\begin{tabular}{|c|c|}
\hline Concepto & Descripción \\
\hline $\begin{array}{l}\text { Características } \\
\text { del área }\end{array}$ & $\begin{array}{l}\text { Menos de } 1200 \text { metros sobre el nivel mar, } \\
\text { con temperatura media anual entre } 22 \text { y } \\
26^{\circ} \mathrm{C} \text {, precipitaciones alrededor de } 1000 \\
\text { mm anuales. }\end{array}$ \\
\hline $\begin{array}{l}\text { Preparación del } \\
\text { terreno }\end{array}$ & 1 barbecho y 1 rastreo \\
\hline Variedades & $\begin{array}{l}\text { Costas: H-507, H-562 y H-563. Resto del } \\
\text { estado: H-507, H-515, H-516, H-562 y H- } \\
563 \text {. }\end{array}$ \\
\hline Siembra & $80 \mathrm{~cm}$ entre surcos \\
\hline $\begin{array}{l}\text { Fecha } \\
\text { siembra }\end{array}$ & $\begin{array}{l}\text { Del } 10 \text { al } 30 \text { Junio y en las Costas hasta el } \\
20 \text { de julio }\end{array}$ \\
\hline $\begin{array}{l}\text { Densidad de } \\
\text { población }\end{array}$ & $\begin{array}{l}20 \text { kilos de semilla, dejando una planta } \\
\text { por mata cada } 20 \text { a } 25 \mathrm{~cm} \text { si se usa } \\
\text { sembradora mecánica, o dos plantas por } \\
\text { mata cada } 40 \text { ó } 50 \text { centímetros si se } \\
\text { siembra a mano lo cual genera una } \\
\text { población de } 55,000 \text { a } 62,500 \text { plantas/ha } \\
\text { y con el genotipo H- } 507 \\
\text { aproximadamente } 47,000 \text { plantas/ha }\end{array}$ \\
\hline Fertilización & $\begin{array}{l}\text { Química: } 90-60-00 \text { (50\% de Nitrógeno y } \\
\text { todo el Fósforo a la siembra y resto a los } \\
45 \text { días). } \\
\text { Biológica: aplicar a la semilla de } 500 \text { a } \\
1000 \text { gr de biofertilizante (micorriza } \\
\text { glomus) por hectárea; si el producto } \\
\text { contiene al menos } 40 \text { esporas por gr de } \\
\text { suelo aplicar } 500 \text { gr de biofertilizante. Si } \\
\text { tiene menos de } 40 \text { esporas por gr de suelo } \\
\text { aplicar } 1000 \text { gr de biofertilizante. }\end{array}$ \\
\hline $\mathrm{N}^{\circ}$ de cultivos & $\begin{array}{l}\text { Debido a que al mover el suelo se pierde } \\
\text { el efecto del herbicida, se aconseja } \\
\text { realizar sólo una labor de cultivo, cuando } \\
\text { el tamaño de la planta todavía lo permita. } \\
\text { Antes de esta labor se recomienda hacer } \\
\text { en la segunda fertilización. }\end{array}$ \\
\hline $\begin{array}{l}\text { Control } \\
\text { maleza }\end{array}$ & $\begin{array}{l}\text { Para controlar las malas hierbas se } \\
\text { sugiere emplear los herbicidas } \\
\text { preemergentes Gesaprim combi, } \\
\text { Gesaprim } 50 \text { o Primagrán en dosis de } 2 \text { a } \\
3 \text { litros por hectárea }\end{array}$ \\
\hline $\begin{array}{lr}\text { Control } & \text { de } \\
\text { plagas } & y \\
\text { enfermedades } & \end{array}$ & $\begin{array}{l}\text { Gusano de alambre, Gallina Ciega } \\
\text { (Counter } 20 \% \text { G } 7 \mathrm{~kg} / \mathrm{ha} \text { ), Gusano } \\
\text { Cogollero (Carbarilo } 10 \mathrm{~kg} / \mathrm{ha} \text { ó Lorsban } \\
480 \mathrm{E} 1 \mathrm{lt} / \mathrm{ha} \text { ), Decis } 0.25 \mathrm{lt} / \mathrm{ha} \text { ó Pounce } \\
\text { Gr. } 5 \mathrm{~kg} / \mathrm{ha}\end{array}$ \\
\hline Cosecha & $\begin{array}{l}\text { Pizca manual, desgrane (desgranadora) y } \\
\text { acarreo. }\end{array}$ \\
\hline $\begin{array}{l}\text { Rendimiento } \\
\text { esperado } \\
\text { (ton/ha) } \\
\end{array}$ & 5.5 \\
\hline $\begin{array}{l}\text { Costo de } \\
\text { producción/ha } \\
(\$)^{*}\end{array}$ & 8,500 \\
\hline $\begin{array}{l}\text { Ingreso bruto/ha } \\
(\$)^{* *}\end{array}$ & 13,750 \\
\hline $\begin{array}{l}\text { Relación } \\
\text { beneficio/costo }\end{array}$ & 1.61 \\
\hline \multicolumn{2}{|c|}{$\begin{array}{l}* \text { Considera los costos directos de los conceptos del paquete. } \\
* * \$ 2,500.00 / \text { ton }\end{array}$} \\
\hline
\end{tabular}

Tabla 2 Paquete tecnológico de alto potencial productivo

\section{Paquete tecnológico para maíz de temporal, ciclo agrícola primavera - verano ${ }^{[8]}$}

\section{Estado: Guerrero}

Nivel de Potencial Productivo: Medio

\begin{tabular}{|c|c|}
\hline Concepto & Descripción \\
\hline $\begin{array}{l}\text { Características } \\
\text { del área }\end{array}$ & $\begin{array}{l}\text { Menos de } 1200 \text { metros sobre el nivel mar, con } \\
\text { temperatura media anual entre } 24 \text { y } 27^{\circ} \mathrm{C} \text {, } \\
\text { precipitaciones entre } 900 \text { y } 1000 \mathrm{~mm} \text { anuales. }\end{array}$ \\
\hline $\begin{array}{l}\text { Preparación del } \\
\text { terreno }\end{array}$ & 1 barbecho y 1 rastreo \\
\hline Variedades & $\begin{array}{l}\text { Costas: H-556, H-516, H-562 y H-563. Resto del } \\
\text { estado: H-556, H-515, H-516, H-562, H-563, } \\
\text { Variedades: VS-535, VS-558, V-559, V-537 C, } \\
\text { V- 234, V-235 }\end{array}$ \\
\hline Siembra & $\begin{array}{l}80 \mathrm{~cm} \text { entre surcos. En el caso de H-556 los } \\
\text { surcos se deberán separar } 90 \mathrm{~cm} \text {. }\end{array}$ \\
\hline $\begin{array}{l}\text { Fecha } \\
\text { siembra }\end{array}$ & $\begin{array}{l}\text { Del } 10 \text { al } 30 \text { Junio y en las Costas hasta el } 20 \text { de } \\
\text { julio }\end{array}$ \\
\hline $\begin{array}{ll}\text { Densidad } \\
\text { población }\end{array}$ & $\begin{array}{l}20 \text { kilos de semilla, dejando una planta por mata } \\
\text { cada } 20 \text { a } 25 \text { centímetros si se usa sembradora } \\
\text { mecánica, o dos plantas por mata cada } 40 \text { ó } 50 \\
\mathrm{~cm} \text { si se siembra a mano. De ambos modos se } \\
\text { obtienen aproximadamente } 55,000 \text { a } 62,500 \\
\text { plantas/ha. En el caso del maíz H- } 507 \text { sembrar } \\
\text { dos plantas cada } 50 \mathrm{~cm} \text { si se siembra a mano, o } \\
\text { una planta por mata cada } 25 \mathrm{~cm} \text { si la siembra es } \\
\text { mecanizada, para tener una densidad de } 47,000 \\
\text { plantas/ha. }\end{array}$ \\
\hline Fertilización & $\begin{array}{l}\text { Química: } 60-30-00 \text { ( } 50 \% \text { de Nitrógeno y todo el } \\
\text { Fósforo a la siembra y resto a los } 45 \text { días). } \\
\text { Biológica: aplicar a la semilla de } 500 \text { a } 1000 \text { gr } \\
\text { de biofertilizante (micorriza glomus) por } \\
\text { hectárea; si el producto contiene al menos } 40 \\
\text { esporas por gr de suelo aplicar } 500 \text { gr de } \\
\text { biofertilizante. Si tiene menos de } 40 \text { esporas por } \\
\text { gr de suelo aplicar } 1000 \text { gr de biofertilizante. }\end{array}$ \\
\hline $\mathrm{N}^{\circ}$ de cultivos & $\begin{array}{l}\text { Debido a que al mover el suelo se pierde el efecto } \\
\text { del herbicida, se aconseja realizar sólo una labor } \\
\text { de cultivo lo más tarde posible, cuando la planta } \\
\text { todavía lo permita. Antes de esta labor se hace la } \\
\text { segunda fertilización, ya que de este modo el } \\
\text { fertilizante queda tapado y no se pierde por } \\
\text { evaporación }\end{array}$ \\
\hline $\begin{array}{l}\text { Control } \\
\text { maleza }\end{array}$ & $\begin{array}{l}\text { Para controlar las malas hierbas se sugiere } \\
\text { emplear los herbicidas preemergentes Gesaprim } \\
\text { combi, Gesaprim } 50 \text { o Primagrán en dosis de } 2 \text { a } \\
3 \text { litros por hectárea }\end{array}$ \\
\hline $\begin{array}{lr}\text { Control } & \text { de } \\
\text { plagas } & y \\
\text { enfermedades }\end{array}$ & $\begin{array}{l}\text { Gusano de alambre, Gallina Ciega (Counter } 20 \% \\
\mathrm{G} 7 \mathrm{~kg} / \mathrm{ha} \text { ), Gusano Cogollero (Carbarilo } 10 \\
\mathrm{~kg} / \mathrm{ha} \text { ó Lorsban } 480 \mathrm{E} 1 \mathrm{lt} / \mathrm{ha} \text { ). } \\
\text { Control biológico. Liberación de } 25 \text { pulgadas de } \\
\text { Trichogramma spp., } 25 \text { cartoncillos de una } \\
\text { pulgada por hectárea. Con frecuencias de } \\
\text { liberaciones de cada } 7 \text { a } 10 \text { días, Desde la } \\
\text { emergencia del cultivo hasta que el grano este } \\
\text { maduro. }\end{array}$ \\
\hline Cosecha & $\begin{array}{l}\text { Pizca manual, desgrane (desgranadora) } \\
\text { acarreo. }\end{array}$ \\
\hline $\begin{array}{l}\text { Rendimiento } \\
\text { esperado } \\
\text { (ton/ha) }\end{array}$ & 4.5 \\
\hline $\begin{array}{l}\text { Costo de } \\
\text { producción/ha } \\
(\$)^{*}\end{array}$ & 8,500 \\
\hline $\begin{array}{l}\text { Ingreso bruto/ha } \\
(\$)^{* *}\end{array}$ & 11,250 \\
\hline $\begin{array}{l}\text { Relación } \\
\text { beneficio/costo }\end{array}$ & 1.32 \\
\hline \multicolumn{2}{|c|}{$\begin{array}{l}* \text { Considera los costos directos de los conceptos del paquete. } \\
* * \$ 2,500.00 / \text { ton }\end{array}$} \\
\hline
\end{tabular}

Tabla 3 Paquete tecnológico de medio potencial productivo 


\section{Paquete Tecnológico para maíz de temporal,} ciclo agrícola primavera - verano $^{[8]}$

\section{Estado: Guerrero}

Nivel de Potencial Productivo: Bajo

\begin{tabular}{|c|c|}
\hline Concepto & Descripción \\
\hline $\begin{array}{l}\text { Características } \\
\text { del área }\end{array}$ & $\begin{array}{l}\text { Áreas ubicadas a menos de } 1600 \text { metros } \\
\text { sobre el nivel mar, con temperaturas } \\
\text { medias anual de } 26 \text { a } 27 \text { o C, y } \\
\text { precipitaciones entre } 900 \text { y } 1000 \mathrm{~mm} \\
\text { anuales. }\end{array}$ \\
\hline $\begin{array}{l}\text { Preparación del } \\
\text { terreno }\end{array}$ & Barbecho y limpia manual \\
\hline Variedades & VS-535, V- 234, V-235, V-559 \\
\hline Siembra & $80 \mathrm{~cm}$ entre surcos. \\
\hline Fecha de siembra & $\begin{array}{l}\text { Del } 10 \text { al } 30 \text { Junio y en las Costas hasta } \\
\text { el } 20 \text { de julio }\end{array}$ \\
\hline $\begin{array}{l}\text { Densidad de } \\
\text { población }\end{array}$ & $\begin{array}{l}20 \text { kilos de semilla, dejando dos plantas } \\
\text { por mata cada } 50 \mathrm{~cm} \text { en siembra a mano } \\
\text { para una población de } 47,000 \text { plantas/ha. }\end{array}$ \\
\hline Fertilización & $\begin{array}{l}\text { Química: } 60-30-00 \text { ( } 50 \% \text { de Nitrógeno y } \\
\text { todo el Fósforo a la siembra y resto a los } \\
45 \text { días). } \\
\text { Biológica: aplicar a la semilla de } 500 \text { a } \\
1000 \text { gr de biofertilizante (micorriza } \\
\text { glomus) por hectárea; si el producto } \\
\text { contiene al menos } 40 \text { esporas por gr de } \\
\text { suelo aplicar } 500 \text { gr de biofertilizante. Si } \\
\text { tiene menos de } 40 \text { esporas por gr de suelo } \\
\text { aplicar } 1000 \text { gr de biofertilizante. }\end{array}$ \\
\hline $\mathrm{N}^{\circ}$ de cultivos & $\begin{array}{l}\text { Realizar dos labores de cultivo cuando la } \\
\text { planta todavía lo permita. Antes de la } \\
\text { segunda labor se hace la segunda } \\
\text { fertilización, ya que de este modo el } \\
\text { fertilizante queda "tapado" y no se pierde } \\
\text { por evaporación }\end{array}$ \\
\hline $\begin{array}{l}\text { Control de } \\
\text { maleza }\end{array}$ & $\begin{array}{l}\text { Realizarla manualmente. Dos escardas } \\
\text { con yunta. La primera a los } 15 \text { y a los } 40 \\
\text { días después de la germinación de la } \\
\text { semilla. }\end{array}$ \\
\hline $\begin{array}{lr}\text { Control de } \\
\text { plagas } & y \\
\text { enfermedades } & \end{array}$ & $\begin{array}{l}\text { Gusano de alambre, Gallina Ciega } \\
\text { (Counter 20\% G } 7 \mathrm{~kg} / \mathrm{ha} \text { ), Gusano } \\
\text { Cogollero (Carbarilo } 10 \mathrm{~kg} / \mathrm{ha} \text { ó Lorsban } \\
480 \mathrm{E} 1 \mathrm{lt} / \mathrm{ha} \text { ). } \\
\text { Control biológico. Liberación de } 25 \\
\text { pulgadas de Trichogramma spp., } 25 \\
\text { cartoncillos de una pulgada por hectárea. } \\
\text { Con frecuencias de liberaciones de cada } \\
7 \text { a } 10 \text { días, Desde la emergencia del } \\
\text { cultivo hasta que el grano este maduro. }\end{array}$ \\
\hline Cosecha & $\begin{array}{l}\text { Pizca manual, desgrane (desgranadora) y } \\
\text { acarreo. }\end{array}$ \\
\hline $\begin{array}{l}\text { Rendimiento } \\
\text { esperado } \\
\text { (ton/ha) }\end{array}$ & 2.5 \\
\hline $\begin{array}{l}\text { Costo de } \\
\text { producción/ha } \\
(\$)^{*}\end{array}$ & 5,000 \\
\hline $\begin{array}{l}\text { Ingreso bruto/ha } \\
(\$)^{* *}\end{array}$ & 6,250 \\
\hline $\begin{array}{l}\text { Relación } \\
\text { beneficio/costo }\end{array}$ & 1.25 \\
\hline \multicolumn{2}{|c|}{$\begin{array}{l}* \text { Considera los costos directos de los conceptos del paquete. } \\
* * \$ 2,500.00 / \text { ton }\end{array}$} \\
\hline
\end{tabular}

Tabla 4 Paquete tecnológico de bajo potencial productivo

\section{Agradecimientos}

Se hace extensivo el agradecimiento al Dr. David H. Noriega Cantú, quien es Investigador del INIFAP, por su excelente apoyo, disponibilidad y atención muy especial a este trabajo, así como a las Ingenieras Gabriela Salgado Mora y Ana Laura Ochoa López, que desarrollaron en equipo las modificaciones al trabajo de investigación en esta segunda fase. 